\title{
THE INFLUENCE OF SOUS-VIDE TREATMENT ON THE FORM OF MOISTURE IN LARGE-VEGETABLE MEAT SYSTEMS
}

\author{
Natalia Sergeevna RODIONOVA*, Evgeniy Sergeevich POPOV ${ }^{1}$, \\ Adriana BIRCA**, Liviu GACEO*** \\ ${ }^{1}$ Dept. of Service technologies, Voronezh State University of Engineering \\ Technologies, Voronezh, Russia, e-mail: e_s_popov@mail.ru \\ 2 “George Bariţiu” University, Braşov, Romania, e-mail: \\ birca_adriana@yahoo.com \\ ${ }^{3}$ Transilvania University of Braşov, Romania, e-mail: gaceul@yahoo.com
}

\begin{abstract}
The current development of the catering industry is due to the improvement of the processes of heat cooking of raw materials. One such area is the use of low-temperature hydrothermal cooking food, pre-vacuum-packed in heat-resistant polymer film. In cooking, spread a combination of rice, chicken and vegetable ingredients: onions and carrots, which allows you to get a dish with high consumer properties. During the study, it was determined the amount of moisture needed to reach the desired consistency of the mixture components to increase the yield of finished products, while providing maximum storage periods. The results show that the addition of water in amounts exceeding 3.0\% of the total weight of food leads to an increase in the mass fraction of free moisture.
\end{abstract}

Keywords: animal raw materials, semi-finished product, vacuum packaging, heat and humidity treatment, Sous-Vide treatment.

\footnotetext{
${ }^{1}$ Corresponding author. Mailing address: Dept. of Service technologies, Voronezh State University of Engineering Technologies, Voronezh, Russia. E-Mail: $\underline{\text { _s_popov@mail.ru }}$
} 


\section{INTRODUCTION}

One of the priorities of the food service industry is to improve the processes of heat cooking of raw materials. This question is relevant in view of the fact that the traditional cooking of heat is accompanied by a substantial loss of weight of semi-finished and finished products.

It is now one of the most promising directions of development of the food industry is the use of an integrated food processing, pre-packed in vacuum bags polymer, followed by thermo-humidity treatment. The technology allows you to store vitamins, proteins, carbohydrates, fats, macro - and micronutrients raw materials in the same state, and contributes to a performance at a higher level compared to conventional heat treatment and guaranteed hygienic safety by increasing the shelf-life (Rodionova et al., 2012).

When preparing meals, tend to use a variety of products to ensure a balanced composition of the finished product in fats, proteins, carbohydrates, macroand micronutrients. In cooking, a combination of common raw materials of plant or animal origin: rice, onions, carrots and chicken, which allows you to get a dish with high consumer properties. These ingredients are in the process of cooking, can be used with different cuts: whole, diced, julienned, in the form of rings, in the form of meat (Bakhtina et al., 2012).

Change in the state of moisture in the product has an effect on the physicochemical and sensory characteristics of products. In connection with this, the aim of the research was to determine the influence of modes of the technology to change the form of moisture binding sites in the study.

\section{MATERIALS AND METHODS}

The object of study was rice-vegetable mixture with chicken, consisting of the following components: long-grain polished rice varieties 1 (GOST 629293), onions (cut cubes $0.5 \times 0.5 \mathrm{~cm}$ ), carrots (cut straw $1.5 \times 0.2 \times 0.2 \mathrm{~cm}$ ), chicken breast (cut into strips large $1.5 \times 0.5 \times 0.2 \mathrm{~cm}$ ).

It is known that pre-hydration of rice ensuring faster on subsequent thermal treatment humid. In this regard, rice was subjected to preliminary hydration at $353 \mathrm{~K}$ for $30 \mathrm{~min}$, followed by mixing the components in the following proportions dishes: Long grain rice $-58.8 \%$, carrot $-8.82 \%$, onion $8.82 \%$, chicken breast $-23,5 \%$ (Rodionova and Popov, 2012).

During the study the amount of water required to achieve the desired consistency of the mixture components was determined, to increase the yield 
of finished products, while providing maximum storage time, which is known to be largely determined by the amount of free moisture in a food facility.

The heat treatment was performed on meal components in the temperature range $333-373 \mathrm{~K}$, pre-vacuum packing in plastic film, the moisture content of coolant being maintained at $100 \%$ in samples of the product to control the degree of culinary readiness, for defined achievement of required consistency of the finished product.

Quantitative and qualitative changes in the forms of moisture binding was analyzed on the basis of the experimental plots of the rate of dehydration and dehydration of samples with moisture FD - 610 «KETT» (Japan)..

\section{RESULTS AND DISCUSSIONS}

Previously, it was identified that enhance the water, before the heat treatment to rice-vegetable mixtures cooked using similar proportions of rice and vegetable components, essential to an amount not exceeding $12.0 \%$ by weight of food, thereby increasing performance and increase sensory output intermediates, without reducing the duration of storage.

When administered in the formulation of animal feed meals (chicken), to consider the amount of moisture released by animal protein denaturation, which under these conditions was from 18 to $20 \%$ when processing large chicken chopped straw. This fact contributes to the formation of additional amounts of moisture in the vacuum bag, which partially compensates for the addition of water prior to heat treatment to components of the dish. In this connection the purpose of the work was to determine the required amount of water, ensuring maximum yield, the desired consistency of the product and its shelf life. The moisture was varied from 0 (control) to $6.0 \%$ weight.

The results obtained at the quantitative and qualitative analysis of changes in the forms of moisture binding are presented in Figures 1 and 2.

The analysis of plots revealed that there are three stages of dehydration: increasing (warming), constant and decreasing speed of the process. This indicates the presence of moisture in the product in various forms during constant speed corresponds to a process of dehydration and removal osmotically immobilized related moisture during decreasing speed - the process of removing chemically bound water. 


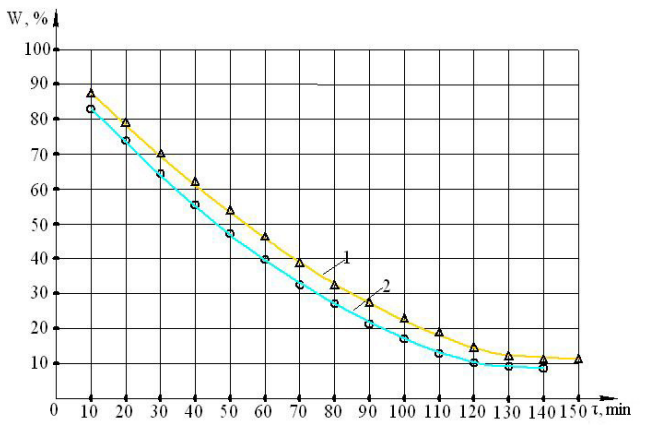

a

w, $\%$ A

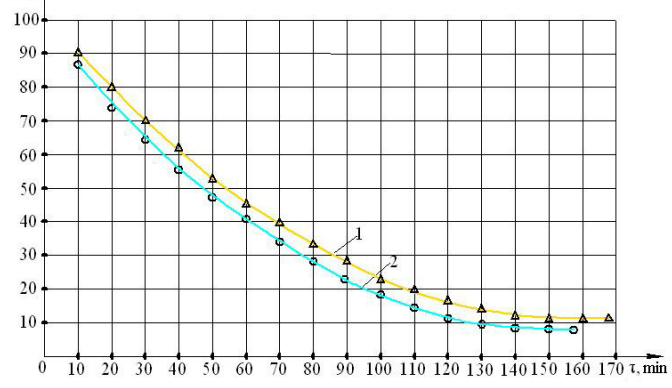

C

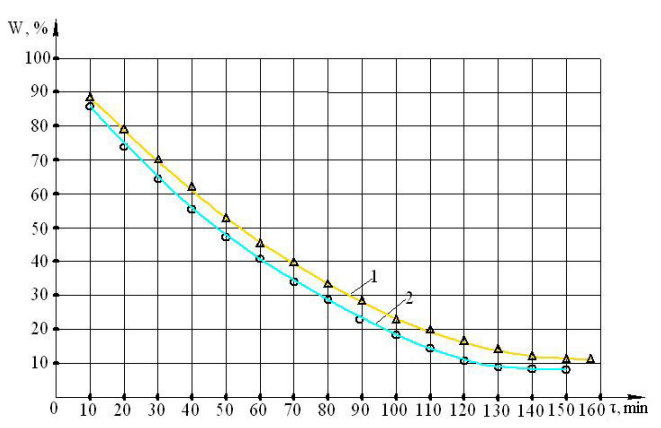

b

Figure 1. Graphical dependences of dehydration of the dishes samples (a - without added water $\mathrm{b}$ - with the addition of water $(3.0 \%) \mathrm{c}$ - with the addition of water

$(6.0 \%))$ processed at different temperatures:

$$
1 \text { - } 333 \mathrm{~K}, 2 \text { - } 373 \mathrm{~K}
$$

It was found that the temperature of thermal treatment humid rice-vegetable mixtures, as well as the amount of overhead water have a significant impact on the free passage of moisture in the bound state.

Based on the analysis presented dependency implies that the duration of the dewatering process rice-vegetable mixtures chicken growing adding water is 140 (at $373 \mathrm{~K})$ - $150 \mathrm{~min}(333 \mathrm{~K})$ - for food samples prepared without addition of water and $150-158$ (at $373 \mathrm{~K}$ ) - 157-168 min (at $333 \mathrm{~K}$ ) - sample dishes prepared with the addition of water in the range $3.0-6.0 \%$.

It should be noted that the dewatering rate is changed in the following ranges: 0.80 to $1.11 \mathrm{~g} / \mathrm{min}(333 \mathrm{~K}, 373 \mathrm{~K})$ - for food samples prepared without addition of water, from 0.83 to $1.33 \mathrm{~g} / \mathrm{min}(333 \mathrm{~K}, 373 \mathrm{~K})$ - sample dishes prepared with the addition of water in the range $3.0-6.0 \%$. 


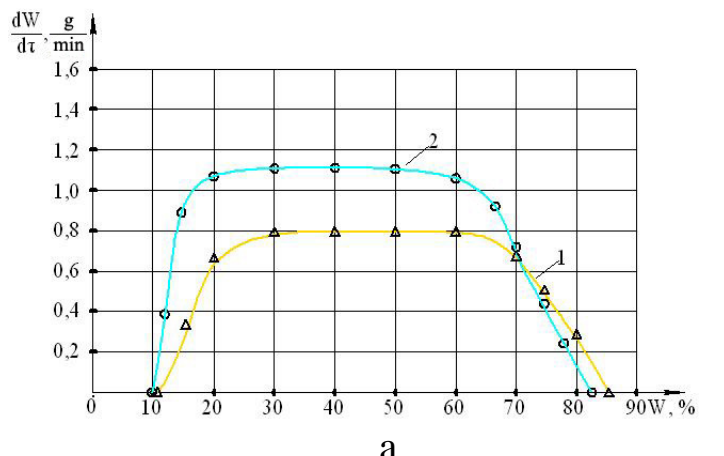

a

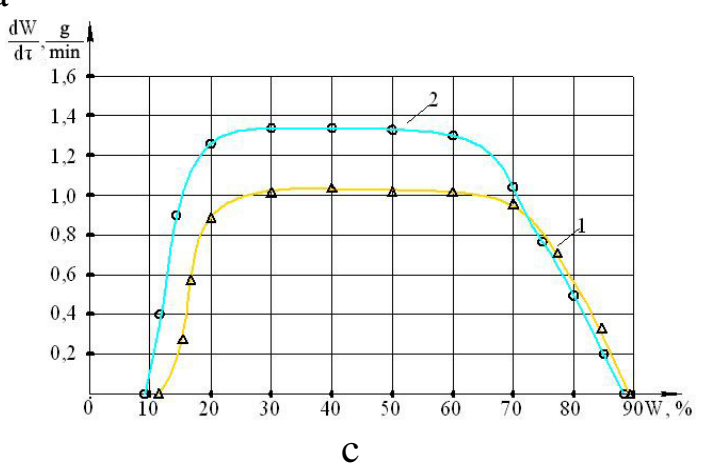

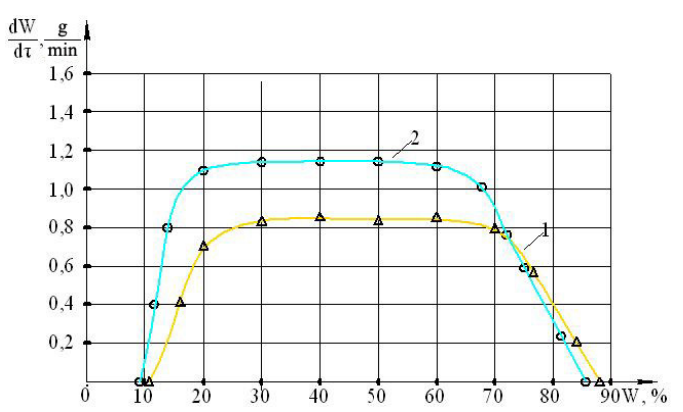

b

Figure 2. Graphical dependences of dehydration of the dishes samples (a - without addition of water, $\mathrm{b}$ - with the addition of water $(3.0 \%) \mathrm{c}$ - with the addition of water $(6.0 \%))$ processed at different temperatures:

$$
1 \text { - } 333 \mathrm{~K}, 2 \text { - } 373 \mathrm{~K}
$$

\section{CONCLUSIONS}

From the analysis of the influence of water on the ratio of free and bound moisture in the samples compared to the control, it was found that the addition of water in an amount exceeding $3.0 \%$ of the total weight of food leads to an increase in the mass fraction of free moisture, which probably corresponds to the maximum attainable degree hydration of polysaccharides of rice in the studied rice-vegetable mixture with chicken. This further increases the amount of water in the formulation, prior to heat treatment tends to reduce the organoleptic characteristics and shortened shelf life of rice-vegetable mixtures with chicken.

Prepared by this technology rice with vegetables and chicken kept at $\mathrm{T}=293$ $295 \mathrm{~K}$ for 2-3 days, which allows it to offer the power of special (field) conditions. 


\section{REFERENCES}

1. Rodionova N.S., Popov E.S., Де-Соуза Л.Д.К. (2012) The study on the effect of pre-hydration on the thermal processing of rice for special nutrition. Storage and processing of agricultural. 3, $25-27$.

2. Rodionova N.S., Popov E.S., Де-Соуза Л.Д.К. (2012) Investigation of the parameters of innovative low-temperature hydrothermal treatment of semifinished vegetables. Herald of the Voronezh State University of Engineering Technology. 4, 10-12.

3. Bakhtina T.I., Popov E.S., Rodionova N.S. (2012) Low-Temperature Processing of Rice, Fish, and Vegetables in Vacuum-Sealed Plastic Pouches. Materials of international conference "IFT \& FoodExpo", LasVegas, USA. 